\title{
Identification of Surgical Plan for Syndesmotic Fixation Procedure Based on Finite Element Method
}

\author{
Tae Sik Goh ${ }^{1,2,+}\left(\mathbb{D}\right.$, Beop-Yong Lim ${ }^{3,4,+}+\mathbb{D}$, Jung Sub Lee ${ }^{1,2}$ and Chi-Seung Lee ${ }^{2,5,6, *(\mathbb{D}}$ \\ 1 Department of Orthopaedic Surgery, Pusan National University Hospital, Busan 49241, Korea; \\ taesikgoh@gmail.com (T.S.G.); jungsublee@pusan.ac.kr (J.S.L.) \\ 2 Biomedical Research Institute, Pusan National University Hospital, Busan 49241, Korea \\ 3 Department of Biomedical Engineering, Graduate School, Pusan National University, Busan 49241, Korea; \\ lbrcj1220@pusan.ac.kr \\ 4 University Research Park of Pusan National University, Busan 49241, Korea \\ 5 Department of Convergence Medicine, School of Medicine, Pusan National University, Busan 49241, Korea \\ 6 Department of Biomedical Engineering, School of Medicine, Pusan National University, Busan 49241, Korea \\ * Correspondence: victorich@pusan.ac.kr; Tel.: +82-51-240-6867; Fax: +82-51-247-3216 \\ + Tae Sik Goh and Beop-Yong Lim contributed equally to this work.
}

Received: 2 April 2020; Accepted: 22 June 2020; Published: 24 June 2020

\begin{abstract}
Syndesmosis injuries account for approximately 20\% of ankle fractures that require surgery. Although multiple surgical options are available, all of them are based on metal screws. Serious complications that arise when applying metal screws include screw loosening or breakage. To prevent such complications, we applied a simulation method using a finite element (FE) analysis. We created a 3D FE model of an ankle joint and conducted an FE analysis focusing on syndesmosis in terms of the level, material, and diameter of the syndesmotic screw and the number of penetrated cortical bones. The magnitude and direction of the force applied to the tibia in the midstance state were considered for simulating the model. The maximum von-Mises stress and syndesmosis widening were analyzed in terms of different biomechanical parameters. We identified the characteristics of the most biomechanically stable syndesmotic screw and its fixation point on the basis of the two parameters. We demonstrated that the ideal syndesmotic screw fixation should be fixed at a level 20 to $25 \mathrm{~mm}$ above the ankle using a $4.5 \mathrm{~mm}$ titanium screw.
\end{abstract}

Keywords: syndesmotic fixation; syndesmotic screw; computational biomechanics; finite element analysis

\section{Introduction}

Ankle fractures are among the most commonly occurring fractures, and in some cases, the distal tibiofibular joint, which is a strong syndesmosis, may be injured [1]. Such a syndesmosis injury is generally due to the mechanisms of pronation-external rotation, pronation-abduction, and supination external rotation [2,3]. If this injury is not properly treated and if the syndesmosis is fixed unstably or in a non-anatomical position, the ankle joint cannot function normally and patients may suffer from serious chronic pain and instability, thus causing post-traumatic arthritis [4]. Despite the recent development in the field of biomechanics, such as bioabsorbable screws and tightrope systems, the metal screw fixation technique is still the dominant treatment method [5]. However, this method has some shortcomings in appropriately selecting the following parameters: the point of screw insertion, the diameter and material of the screw, and the number of cortical bone penetrations [4]. In this method, an incision is made on the outside of the ankle and the position of the syndesmosis is corrected. Metal screws are then inserted to fix it. Generally, 1-2 screws are inserted from the fibula to the tibia and placed at a distance in the range of $20-30 \mathrm{~mm}$ above the tibia plafond [6]. However, many cadaveric studies, which 
form the basis of syndesmosis surgeries, have statistical errors and depend on a simple experimental setting. Hence, it is essential to review the location where the syndesmotic screw is fixed in existing approaches [6].

Certain types of materials and materials with specific diameters are used for syndesmotic screws, which are widely employed in clinical practice. The screws are inserted at an appropriate level, and the number of cortical bones that require penetration is selected on the basis of the surgical method used. Titanium or stainless steel is used as the material for the screw, the diameter of which is either 3.5 or $4.5 \mathrm{~mm}$, respectively. The screw is inserted at a distance ranging from 20 to $30 \mathrm{~mm}$ above the tibia plafond, and 3 or 4 cortical bones are penetrated for the surgery [7]. However, studies have shown that patients suffer from post-surgical complications, such as bone breakage near the screws and screw loosening or breakage $[1,8]$. To prevent these complications, we need to conduct an experimental measurement wherein the internal stress distributions of the distal tibiofibular joint and screw are checked when the load applied to the syndesmosis exceeds a certain limit, and subsequently, measure the displacement of the syndesmosis in a quantitative manner. Thus, it is necessary to compare the insertion location and the dimensions of the screw from a biomechanical perspective.

Many existing studies have determined the most favorable point for syndesmotic screw insertion by conducting cadaveric experiments and finite element (FE) analyses. The experiments and analyses have been conducted considering only 1 or 2 parameters among the following: the diameter, number, and level of the screw, and motion of the ankle joint. As a result of these studies, the displacement and angle of the bone, syndesmosis clear space, and maximum stress of the bone have been determined with insufficient evidence [4,9-12]. Unfortunately, as cadaveric experiments are restricted by limitation on the number of available specimens, not all the parameters have been analyzed in the experimental plan. Therefore, the results obtained using FE analyses considering only one or two parameters are inaccurate in comparison to studies wherein multiple parameters are considered, as a disease can have various causes.

Hence, in this study, we used an FE analysis and considered the following four parameters: level, diameter, material of the syndesmotic screw and number of penetrated cortical bones. We obtained relevant results from the analysis and determined a more accurate and favorable position for screw insertion. As existing studies on FE analyses have failed to determine the parameters such as the material of the screw and the number of cortical bone penetrations, we believe this study is novel.

\section{Materials and Methods}

The procedure and method of the FE analysis are described briefly as follows. The computed tomography (CT) image of a patient was obtained using a CT scanner. A 3D model of the syndesmosis was extracted from this CT image using the Mimics 22.0 software (Materialise NV, Leuven, Belgium). A 3D syndesmotic screw was modeled in SOLIDWORKS 2019 (Dassault Systèmes, Vélizy-Villacoublay, France). Finally, the results were verified using an FE analysis program, ANSYS 2019 R1 (ANSYS Inc., Canonsburg, PA, USA).

\subsection{Fabrication of 3D Models of Ankle and Syndesmotic Screw for Finite Element Analysis}

The cortical bone, cancellous bone, and ligaments are essential parts of the ankle from clinical and biomechanical perspectives. In particular, the tibia, fibula, talus, and calcaneus need to be included in the 3D model. We selected a suitable patient for the study and captured the CT image of the required part using the CT scanner. The patient was a 32-year-old healthy man, whose condition had been checked in the hospital.

The CT image was obtained using radiography with an interval of $0.625 \mathrm{~mm}$. This image was imported into the Mimics 22.0 program to extract the necessary bone part and create a 3D model. As the surface of the 3D model at this stage is quite rough and has many pores, we filled the pores and smoothened the surface. If the model has an irregular surface or a complex shape, the results of the FE analysis become less reliable, i.e., the error increases. Therefore, the model should be simplified. 
The complete model comprises the following parts: tibia, fibula, talus, and calcaneus. Each part was modeled in its Hounsfield unit of the cortical and cancellous bones.

Next, we considered the ligaments, which have the largest effect on the mechanical motion of the bone. The different bones are connected using the ligaments, as shown in Figure 1. The ligaments were classified into anterior talofibular, calcaneofibular, posterior talofibular, deep deltoid, and interosseous membrane. The insertion point of each ligament was determined on the basis of the anatomical data. Figure 1 shows the 3D models of the bones and ligaments.

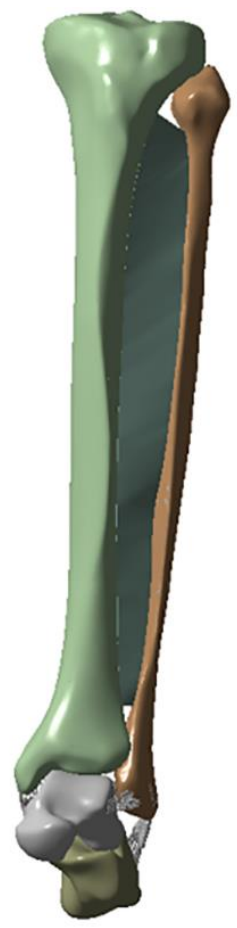

(a)

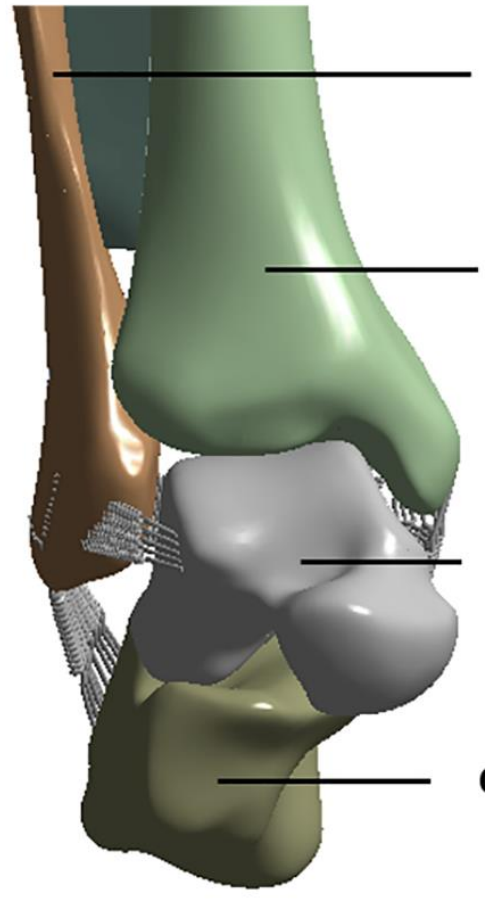

(b)

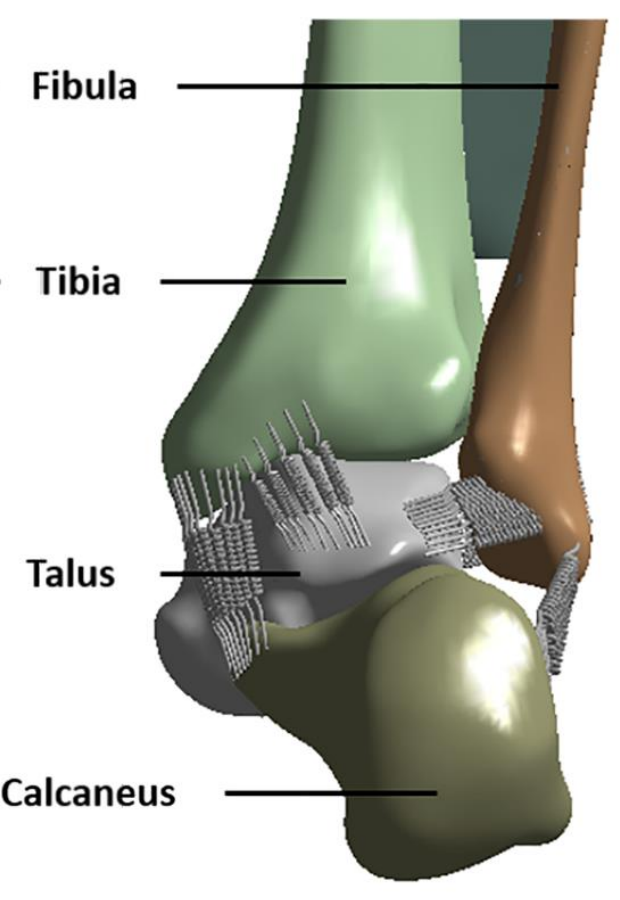

(c)

Figure 1. 3D models of the ankle bone and ligaments: (a) frontal view, (b) anterior ligaments, and (c) posterior ligaments.

The syndesmotic screw, which needs to be included in the 3D model of the ankle, was modeled using the SOLIDWORKS 2019 software. The selected diameters of the screw were 3.5 and $4.5 \mathrm{~mm}$, and the lengths selected were $40,45,50,55$, and $60 \mathrm{~mm}$. As the length was determined on the basis of the number of penetrated cortical bones, we considered which of the five classes of length could penetrate three or four cortical bones. If the screw penetrates the fibula and fixes into the tibia, the screw is assumed to have penetrated three cortical bones. However, if the screw penetrates both the fibula and the tibia, it is said to have penetrated four cortical bones. In addition, the levels of the screws were 10, 15, 20, and $25 \mathrm{~mm}$ from the tibiofibular joint. As the widths of the tibia and fibula vary depending on the screw level, we considered this fact in determining the length. In summary, 16 types of screws were fabricated on the basis of two different diameters, two different numbers of penetrated cortical bones, and four levels.

The fabricated screws were included in the complete 3D ankle model. The insertion point was clinically verified from a syndesmotic screw fixation technique. With this point set, the screw level was varied to insert each screw. Table 1 lists the specifications of the model. 
Table 1. Specifications of the finite element model.

\begin{tabular}{cc}
\hline Parameter & Value (Unit) \\
\hline Screw level & $10,15,20$, and $25(\mathrm{~mm})$ \\
Diameter of screw & 3.5 and $4.5(\mathrm{~mm})$ \\
Material of screw & Titanium and stainless steel \\
Number of penetrated cortical bones & 3 and 4 \\
\hline
\end{tabular}

\subsection{Finite Element Analysis}

We conducted the FE analysis using the ANSYS 2019 R1 software. We imported the 3D models of the ankle and screw into the ANSYS program and inputted various biomechanical parameters for the model analysis. The results of the analysis are discussed herein.

The parameters, which were inputted to the program to obtain desirable results, include the material property, contact condition, meshing style, and load condition. In this study, material properties were assigned to the cortical bone, cancellous bone, ligaments, and syndesmotic screw. As titanium and stainless steel were selected as the two types of screw materials, the properties of each material were inputted. The materials were assumed isotropic, nonlinearly elastic and plastic, and homogeneous. Tables 2 and 3 list the properties of the various materials [10,11,13-19]. In the case of titanium and stainless steel, the exact characteristics of the material should be reflected. Therefore, the stress-strain curve of each material was used for the analysis [20,21].

Table 2. Properties of various materials.

\begin{tabular}{cccc}
\hline & Young's Modulus (MPa) & Poisson's Ratio & $\begin{array}{c}\text { Tensile/Compressive Ultimate } \\
\text { Strength (MPa) }\end{array}$ \\
\hline Cortical bone & 17.000 & 0.3 & 230 \\
Cancellous bone & 700 & 0.2 & 6 \\
Interosseous membrane & 260 & 0.49 & 45 \\
Screw (Titanium: Ti-6Al-4V) & 106.000 & 0.33 & 896 \\
Screw (Stainless steel: 316L) & 193.000 & 0.27 & 584 \\
\hline
\end{tabular}

Table 3. Properties of ankle joint ligaments.

\begin{tabular}{cc}
\hline Ligaments & Stiffness $\mathbf{( N / c m )}$ \\
\hline Anterior talofibular & 399.9 \\
Calcaneofibular & 705.1 \\
Posterior talofibular & 397.5 \\
Deep deltoid & 1288.2 \\
\hline
\end{tabular}

With regard to the contact condition, we need to set the relationship between the two bones and that between a bone and the syndesmotic screw. The contact between the tibia, fibula, talus, and calcaneus was set for the bonded friction condition, and the friction coefficient was set to 0.1 [19]. Similarly, the contact between the screw and a bone was set for the friction condition, and the friction coefficient was $0.7[22,23]$. In this study, the screw thread was simplified for ease of analysis. However, this was contrary to more accurate interpretation; thus, screw characteristics were considered in the contact between the screw and bone. Screw characteristics such as thread diameter, core diameter, thread pitch, and thread angle were in accordance with the standard metallic medical bone screw (F543-13) of the American Society for Testing and Materials (ASTM). This contact was the pure penalty contact algorithm and the simulations were conducted under ideal osseointegration conditions.

Meshing is the most important process for enhancing the accuracy and convergence of an FE analysis. The cortical and cancellous bones were meshed using tetrahedral elements because of their irregular shapes, whereas hexahedral elements were selected for the membrane ligament and screw. 
As the ligaments were assumed to be formed by multiple lines with negligible area, they were modeled using spring elements. A total of 80,918 elements and 149,613 nodes were used for the FE models.

The physical motion of the lower body of a walking person is generally divided into five motions: heel strike, foot flat, midstance, heel-off, and toe-off. In this study, we selected the midstance motion for the FE models. The loads on the tibia due to the midstance motion include a compressive force of $2352 \mathrm{~N}$ and a tangential force of $235 \mathrm{~N}$ [24].

This study also evaluated the sensitivity of elements that affected the accuracy of the results, prior to performing the regular FE analysis. The coarse, medium, and fine densities of three representative meshes were selected to determine the number of elements, as shown in Figure 2. An analysis was performed using the three densities, and the results converged from medium to fine-mesh densities. Table 4 lists the number of elements, number of nodes, computational time, and equivalent stress on the screw/bone for each density. Convergence and accuracy increased for the fine mesh; however, it cannot be applied in practice because of the increased computational time. Therefore, a medium mesh with a high degree of convergence was selected for the analysis.

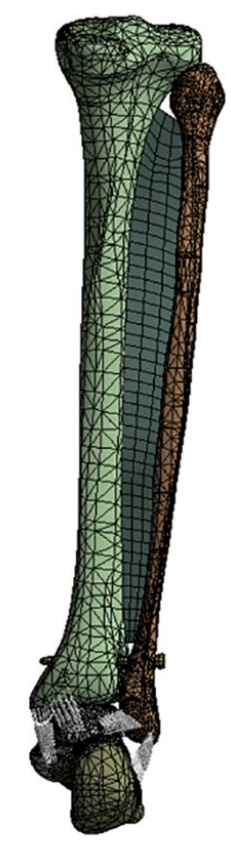

(a)

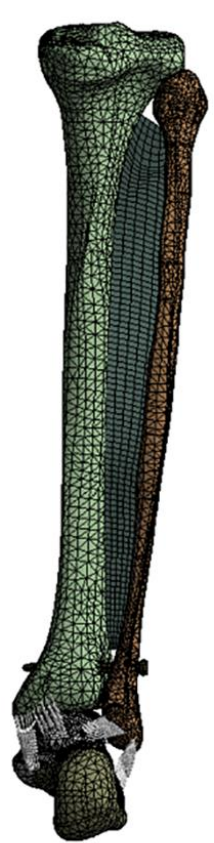

(b)
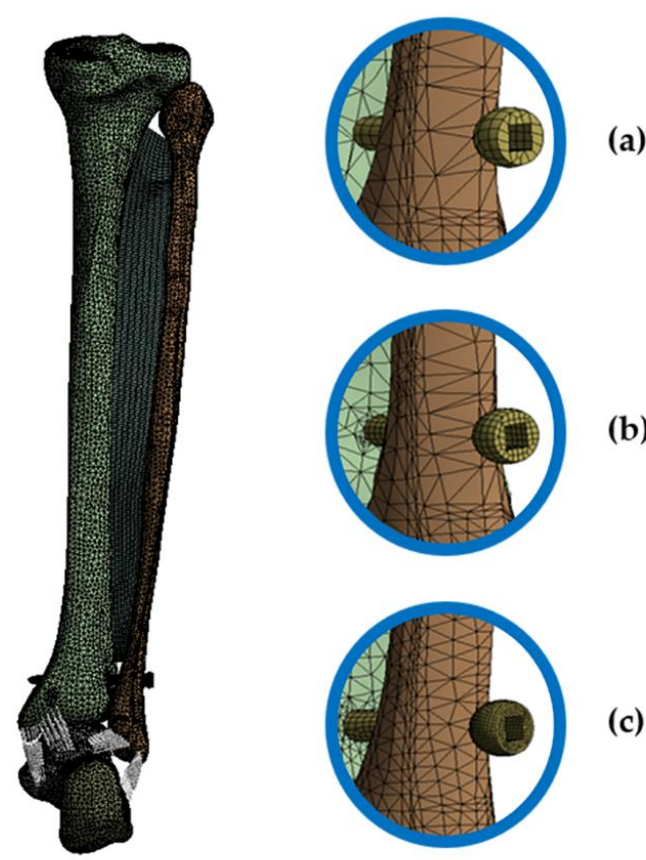

(c)

Figure 2. Classification according to the mesh densities to evaluate the sensitivity of the elements: (a) shows the coarse mesh, (b) shows the medium mesh, and (c) shows the image of the fine mesh.

Table 4. Analysis of state and influence on interpretation by mesh densities.

\begin{tabular}{cccc}
\hline & Coarse & Medium & Fine \\
\hline Number of elements & 51.657 & 80.918 & 271.882 \\
Number of nodes & 92.875 & 149.613 & 498.461 \\
Approximate computational time (min) & 100 & 120 & 1400 \\
Stress on the screw (MPa) & 320.24 & 344.13 & 346.22 \\
Syndesmosis widening (mm) & 0.0587 & 0.0682 & 0.0715 \\
\hline
\end{tabular}

Compressive forces need to be applied to two anatomical locations when the upper part of the tibia is acted upon by a force. To simulate this, we applied a compressive force of $941 \mathrm{~N}$, which was $40 \%$ of the total compressive force, to the left of the upper tibia and the remaining $1411 \mathrm{~N}$ to the right [11]. 
In addition, the lower parts of the talus and calcaneus served as fixed supports, as they are fixed under actual conditions. Figure 3 shows the models under the different conditions that were applied.

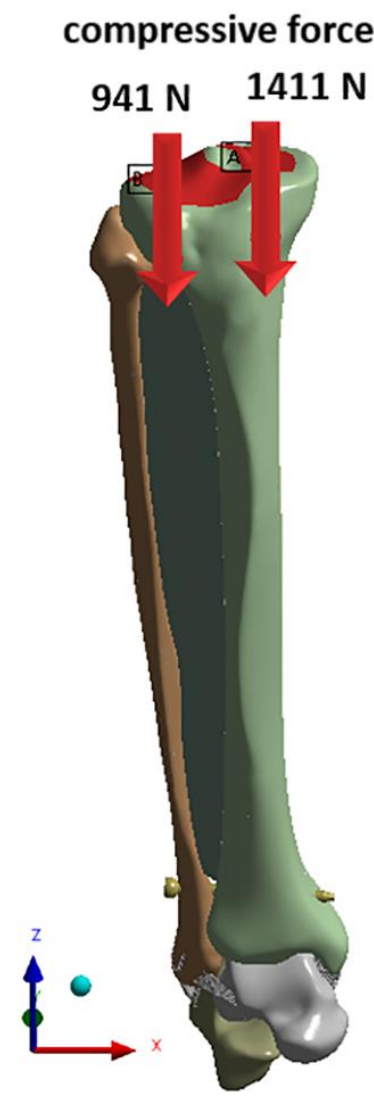

(a)

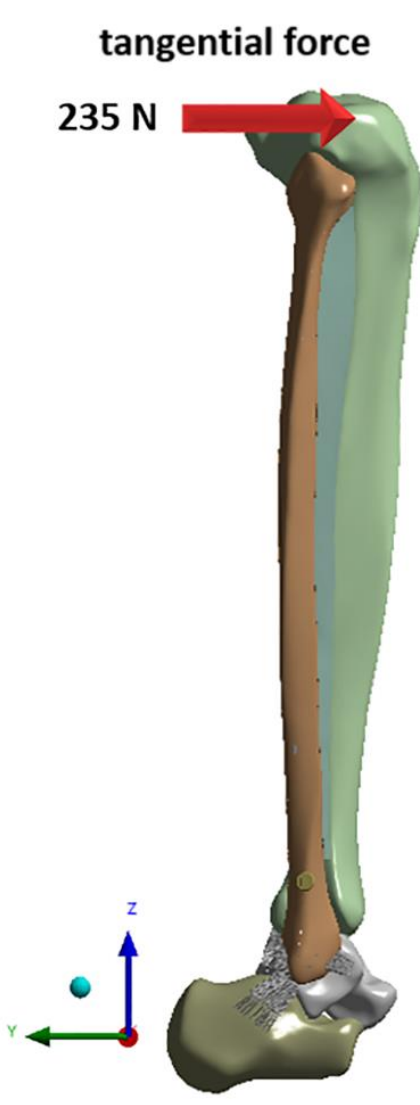

(b)

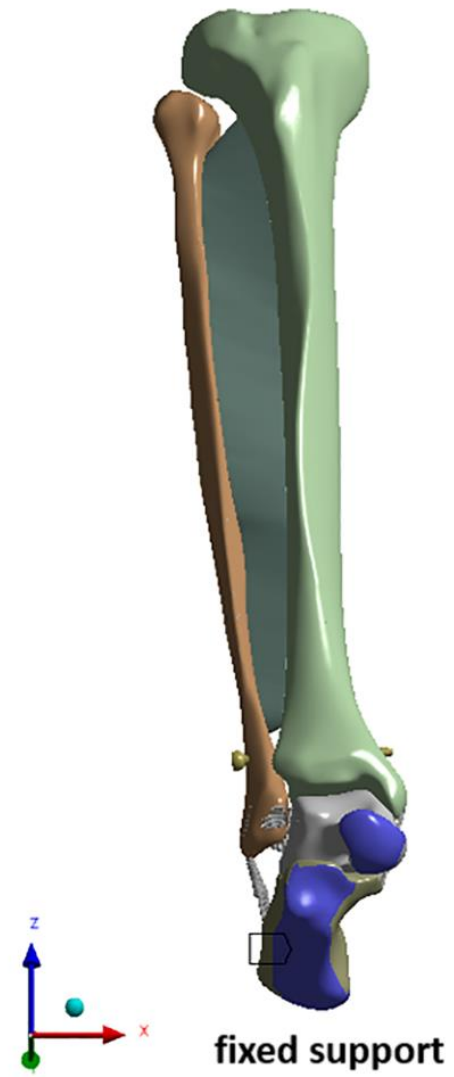

(c)

Figure 3. Loading conditions applied to the finite element (FE) model: (a) compressive force, (b) tangential force, and (c) fixed support.

After analyzing the FE models under the different biomechanical conditions, we analyzed the maximum von Mises stresses of the screw and the syndesmosis widening. In addition, we performed the FE analysis on each type of syndesmotic screw modeled above and obtained the corresponding results.

\section{Results}

After completing the FE analysis of each type of syndesmotic screw, the data were outputted, as shown in Figures 4 and 5. Tables 5-8 show the analysis of the maximum von Mises stresses and syndesmosis widening results. 


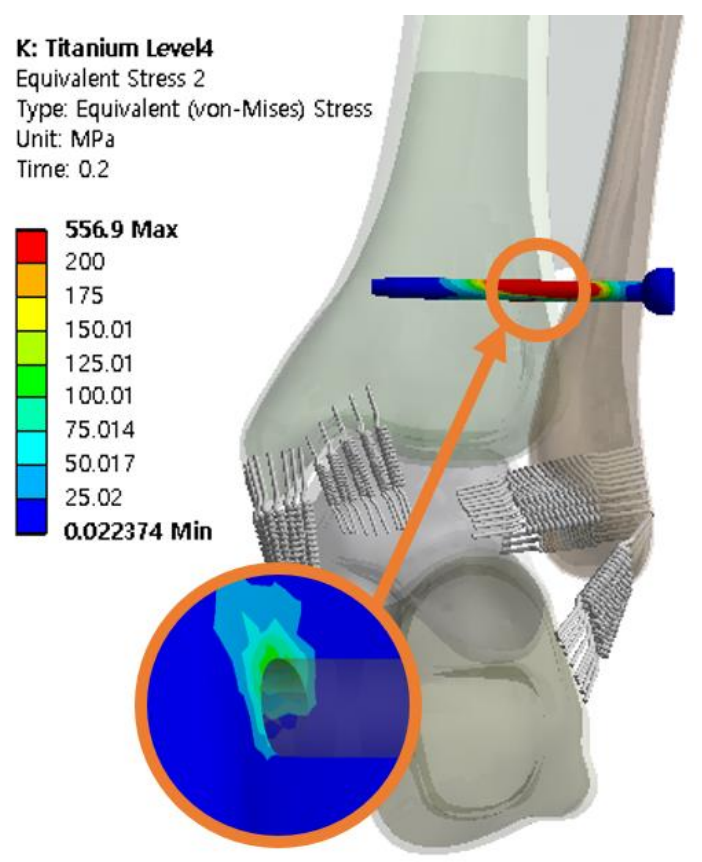

(a)

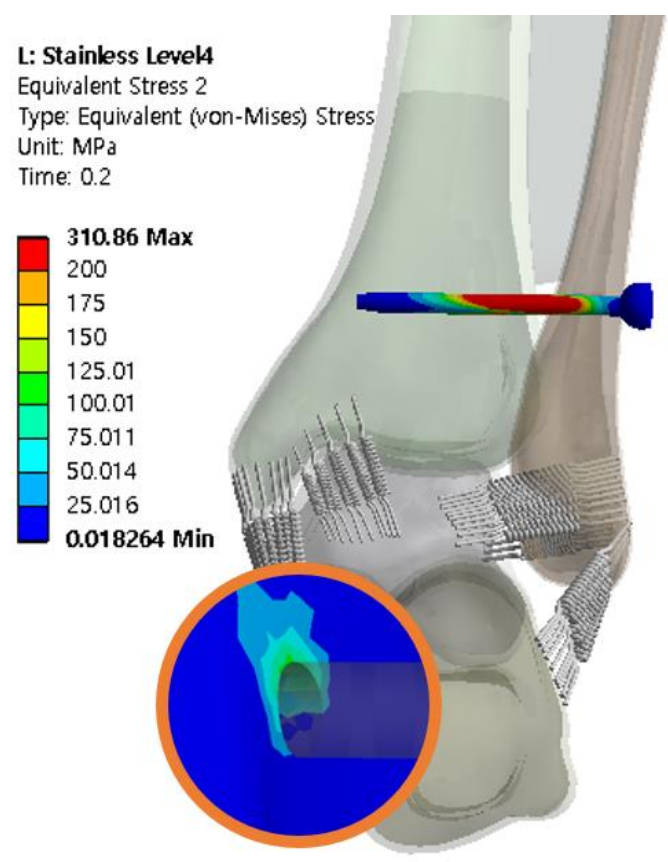

(b)

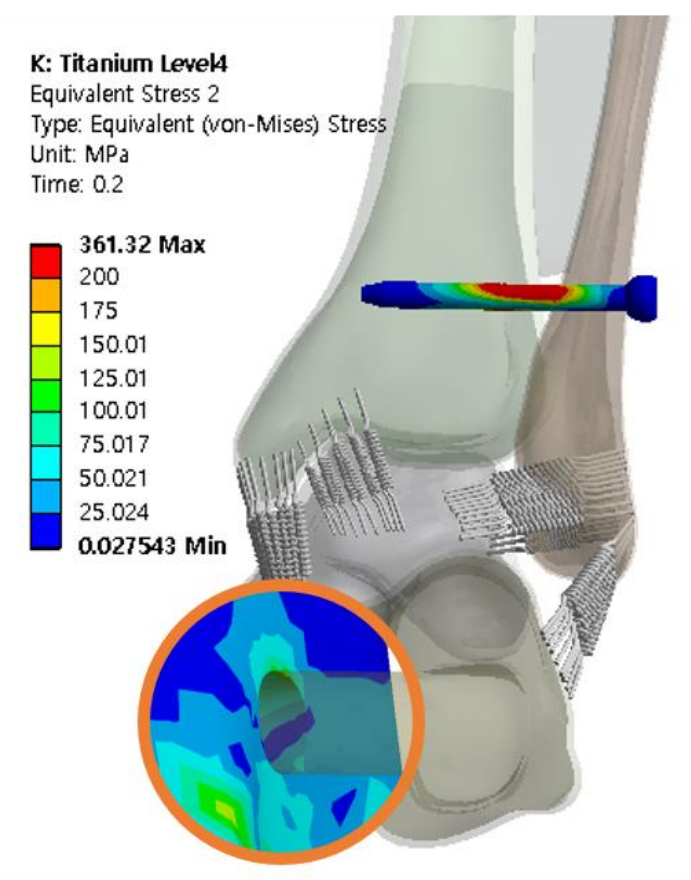

(c)

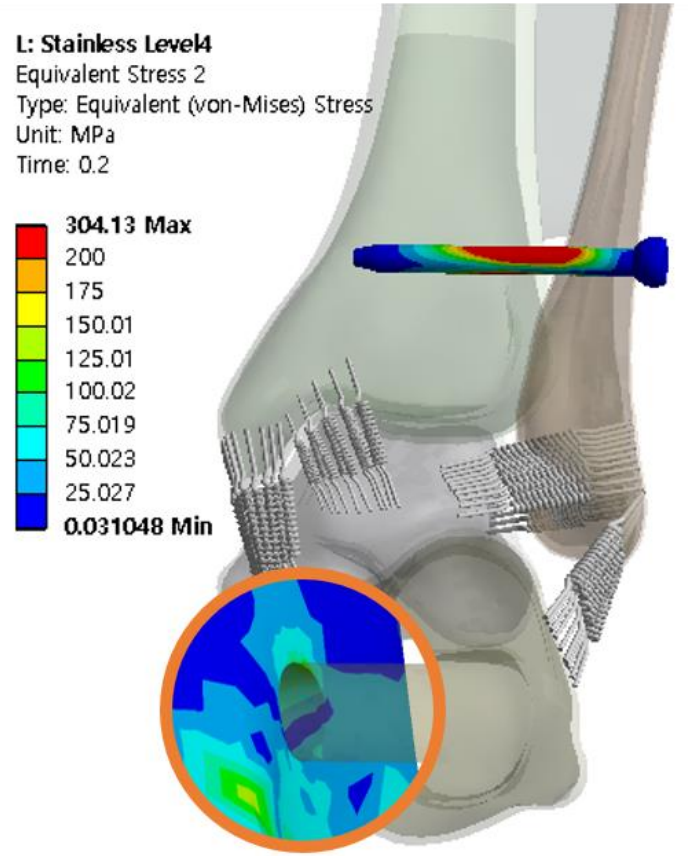

(d)

Figure 4. The von Mises stresses of the syndesmotic screw and adjacent bone at screw level of $25 \mathrm{~mm}$ with three cortical bones purchased: (a) titanium screw with a diameter of $3.5 \mathrm{~mm}$, (b) stainless steel screw with a diameter of $3.5 \mathrm{~mm}$, (c) titanium screw with a diameter of $4.5 \mathrm{~mm}$, (d) stainless steel screw with a diameter of $4.5 \mathrm{~mm}$. 


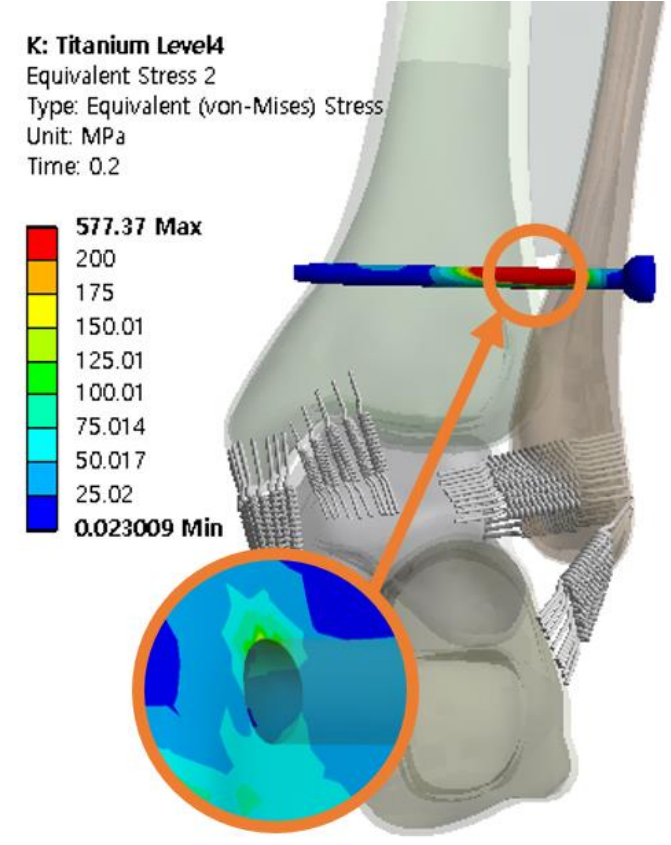

(a)

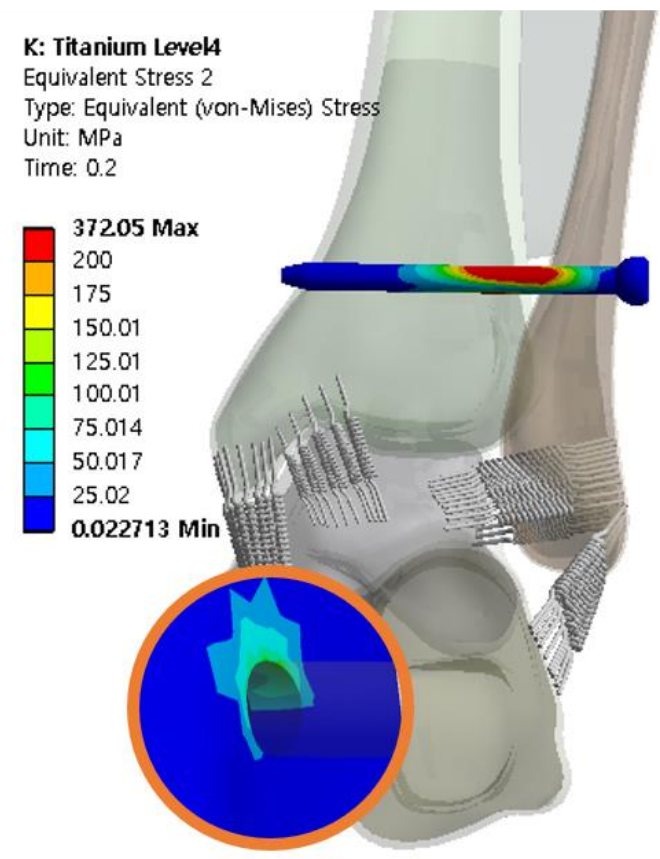

(c)

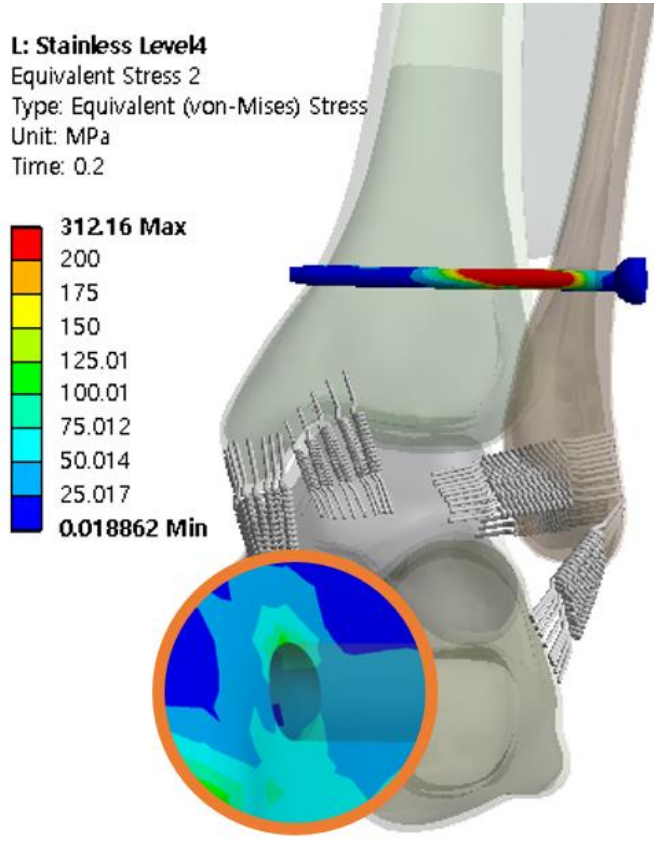

(b)

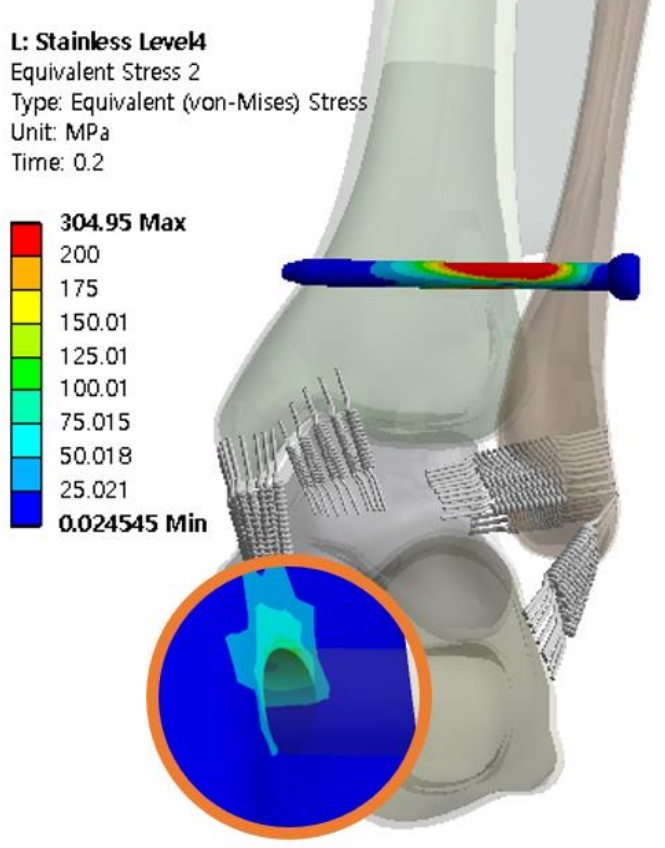

(d)

Figure 5. The von Mises stresses of the syndesmotic screw and adjacent bone at screw level of $25 \mathrm{~mm}$ with four cortical bones purchased: (a) titanium screw with a diameter of $3.5 \mathrm{~mm}$, (b) stainless steel with a diameter of $3.5 \mathrm{~mm}$, (c) titanium screw with a diameter of $4.5 \mathrm{~mm}$, and (d) stainless steel screw with a diameter of $4.5 \mathrm{~mm}$. 
Table 5. Maximum von Mises stresses and syndesmosis widening: titanium screw with three cortical bones purchased.

\begin{tabular}{ccccc}
\hline \multirow{2}{*}{ Diameter $(\mathbf{m m})$} & Level $(\mathbf{m m})$ & \multicolumn{2}{c}{ Maximum von Mises Stress (MPa) } & $\begin{array}{c}\text { Syndesmosis } \\
\text { Widening }(\mathbf{m m})\end{array}$ \\
\cline { 3 - 4 } & & Screw & Adjacent Bone & \\
\hline 3.5 & 10 & 572.85 & 158.04 & 1.0036 \\
3.5 & 15 & 561.33 & 159.34 & 0.3838 \\
3.5 & 20 & 542.85 & 222.02 & 0.2003 \\
3.5 & 25 & 556.90 & 127.28 & 0.0479 \\
4.5 & 10 & 376.49 & 183.99 & 0.0764 \\
4.5 & 15 & 370.14 & 186.13 & 0.0380 \\
4.5 & 20 & 370.28 & 214.93 & 0.0342 \\
4.5 & 25 & 361.32 & 130.21 & 0.0327 \\
\hline
\end{tabular}

Table 6. Maximum von Mises stresses and syndesmosis widening: titanium with four cortical bones purchased.

\begin{tabular}{ccccc}
\hline \multirow{2}{*}{ Diameter (mm) } & Level (mm) & \multicolumn{2}{c}{ Maximum von Mises Stress (MPa) } & $\begin{array}{c}\text { Syndesmosis } \\
\text { Widening }(\mathbf{m m})\end{array}$ \\
\cline { 3 - 4 } & & Screw & Adjacent Bone & \\
\hline 3.5 & 10 & 611.60 & 206.07 & 0.6722 \\
3.5 & 15 & 574.21 & 179.42 & 0.4707 \\
3.5 & 20 & 550.93 & 161.62 & 0.1095 \\
3.5 & 25 & 577.37 & 142.97 & 0.0117 \\
4.5 & 10 & 370.49 & 202.59 & 0.1526 \\
4.5 & 15 & 368.86 & 139.03 & 0.1179 \\
4.5 & 20 & 344.13 & 170.35 & 0.0682 \\
4.5 & 25 & 372.05 & 115.01 & 0.0891 \\
\hline
\end{tabular}

Table 7. Maximum von Mises stresses and syndesmosis widening: stainless steel screw with three cortical bones purchased.

\begin{tabular}{ccccc}
\hline \multirow{2}{*}{ Diameter $(\mathbf{m m})$} & Level $(\mathbf{m m})$ & \multicolumn{2}{c}{ Maximum von Mises Stress (MPa) } & $\begin{array}{c}\text { Syndesmosis } \\
\text { Widening }(\mathbf{m m})\end{array}$ \\
\cline { 3 - 4 } & & Screw & Adjacent Bone & \\
\hline 3.5 & $\mathbf{1 0}$ & 339.51 & 158.80 & 0.8457 \\
3.5 & 15 & 331.52 & 122.77 & 0.4571 \\
3.5 & 20 & 322.58 & 218.66 & 0.3005 \\
3.5 & 25 & 310.86 & 111.07 & 0.2947 \\
4.5 & 10 & 306.51 & 179.14 & 0.1680 \\
4.5 & 15 & 303.12 & 183.27 & 0.1008 \\
4.5 & 20 & 306.65 & 213.48 & 0.1193 \\
4.5 & 25 & 304.13 & 131.49 & 0.0738 \\
\hline
\end{tabular}

Table 8. Maximum von Mises stresses and syndesmosis widening: stainless steel screw with four cortical bones purchased.

\begin{tabular}{ccccc}
\hline \multirow{2}{*}{ Diameter (mm) } & Level (mm) & \multicolumn{2}{c}{ Maximum von Mises Stress (MPa) } & $\begin{array}{c}\text { Syndesmosis } \\
\text { Widening }(\mathbf{m m})\end{array}$ \\
\cline { 3 - 4 } & & Screw & Adjacent Bone & 0.4217 \\
3.5 & 10 & 346.58 & 192.24 & 0.1504 \\
3.5 & 15 & 345.39 & 177.06 & 0.1292 \\
3.5 & 20 & 325.30 & 158.60 & 0.0752 \\
3.5 & 25 & 312.16 & 126.25 & 0.2123 \\
4.5 & 10 & 310.08 & 206.35 & 0.1608 \\
4.5 & 15 & 310.96 & 128.06 & 0.1062 \\
4.5 & 20 & 305.58 & 179.07 & 0.0696 \\
4.5 & 25 & 304.95 & 111.87 & \\
\hline
\end{tabular}


The maximum von Mises stress is the maximum stress acting on the engaged syndesmotic screw and adjacent bone of the screw. This stress was measured by applying a load to the tibia. The values of the maximum von Mises stresses, listed in Tables 5-8, show that the stresses decrease with an increase of the screw level from 10 to $25 \mathrm{~mm}$. Figures $6-11$ show the graph of the stress results at the syndesmotic screw and adjacent bone of the screw, to facilitate the understanding of the stress trend for the remaining parameters.

Figure 6 shows that the maximum von Mises stress of the stainless steel screw is lower than that of the titanium screw. As shown in Figure 7, the stress is lower for a diameter of $4.5 \mathrm{~mm}$ compared with that for a diameter of $3.5 \mathrm{~mm}$. The maximum von Mises stresses are slightly lower for cases wherein three cortical bones are penetrated compared with other cases, as shown in Figure 8.

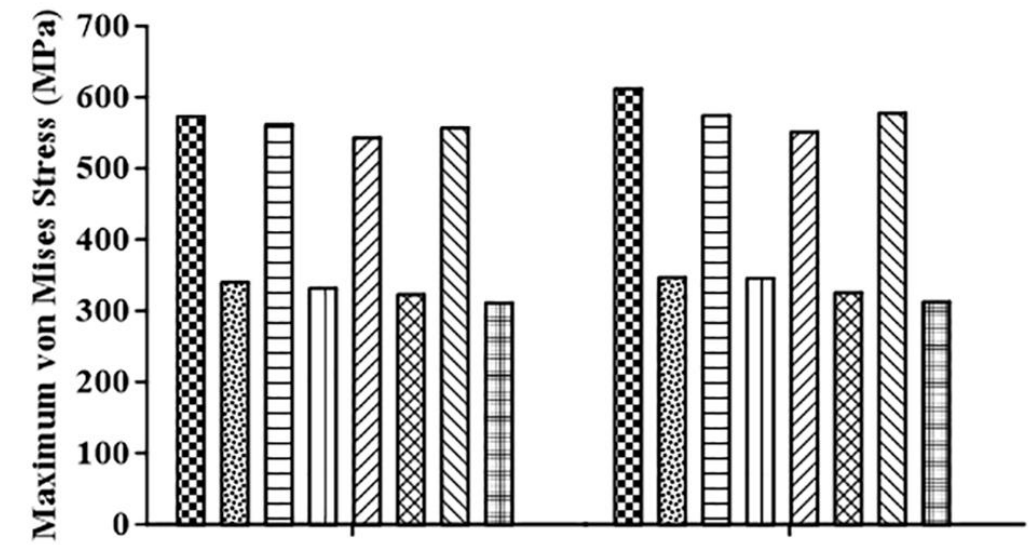

(a) $3.5 \mathrm{~mm}, 3$ cortical

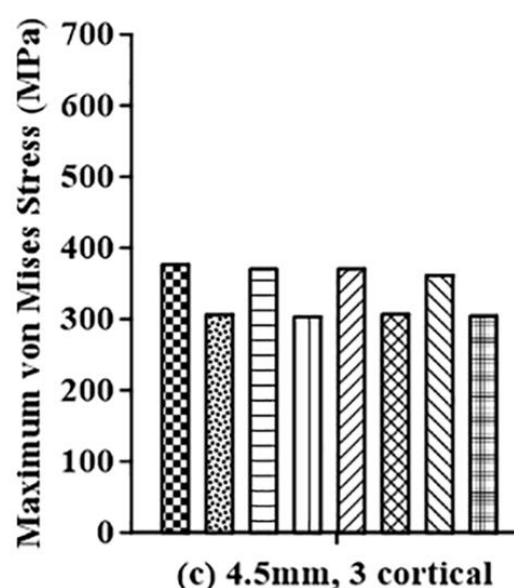

Figure 6. Analysis of the maximum von Mises stresses of the syndesmotic screw in terms of the syndesmotic screw material for screws with diameters of: (a) $3.5 \mathrm{~mm}$ penetrating three cortical bones, (b) $3.5 \mathrm{~mm}$ penetrating four cortical bones, (c) $4.5 \mathrm{~mm}$ penetrating three cortical bones, and (d) $4.5 \mathrm{~mm}$ penetrating four cortical bones.

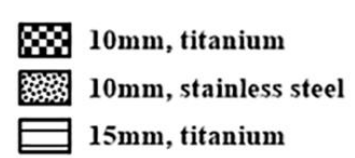

(b) $3.5 \mathrm{~mm}, 4$ cortical

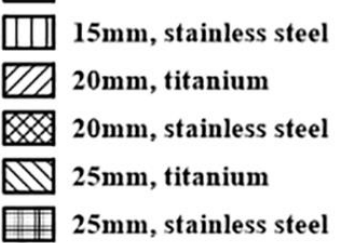

(c) $4.5 \mathrm{~mm}, 3$ cortical

(d) $4.5 \mathrm{~mm}, 4$ cortical

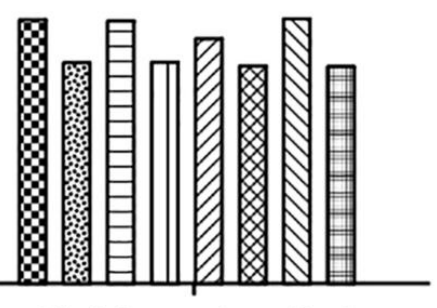




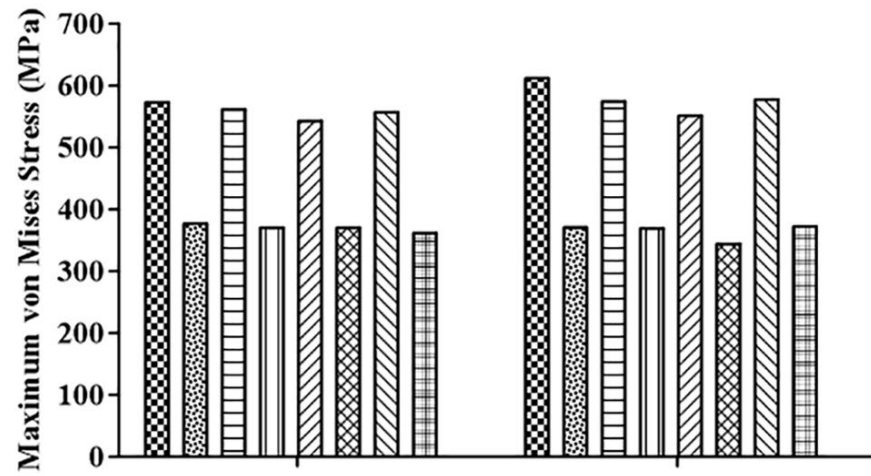

(a) Titanium, 3 cortical

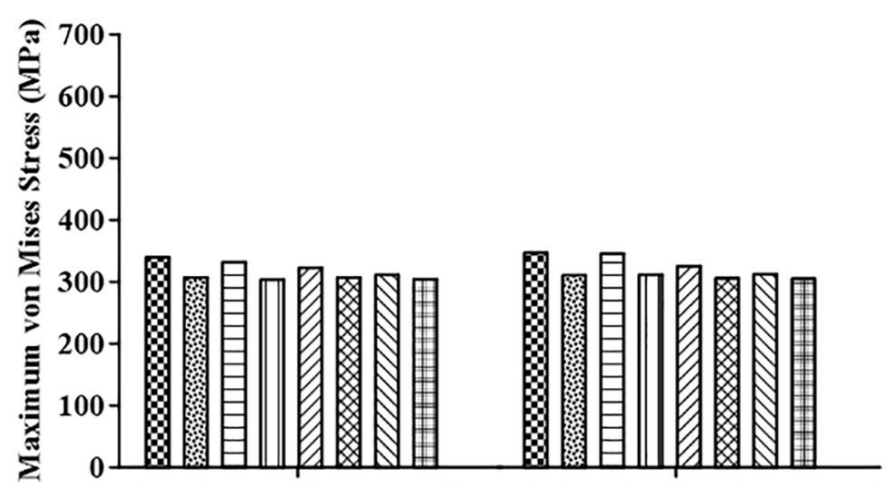

(c) Stainless steel, 3 cortical

\& $10 \mathrm{~mm}, \mathrm{D}=3.5 \mathrm{~mm}$

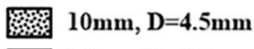

$15 \mathrm{~mm}, \mathrm{D}=3.5 \mathrm{~mm}$

미 $15 \mathrm{~mm}, \mathrm{D}=4.5 \mathrm{~mm}$

Z7 $20 \mathrm{~mm}, \mathrm{D}=3.5 \mathrm{~mm}$

$20 \mathrm{~mm}, \mathrm{D}=4.5 \mathrm{~mm}$

DV $25 \mathrm{~mm}, \mathrm{D}=3.5 \mathrm{~mm}$

$25 \mathrm{~mm}, \mathrm{D}=4.5 \mathrm{~mm}$

Figure 7. Analysis of the maximum von Mises stresses of the syndesmotic screw in terms of the diameter of the syndesmotic screw for: (a) titanium screw penetrating three cortical bones, (b) titanium screw penetrating four cortical bones, (c) stainless steel screw penetrating three cortical bones, and (d) stainless steel screw penetrating four cortical bones.

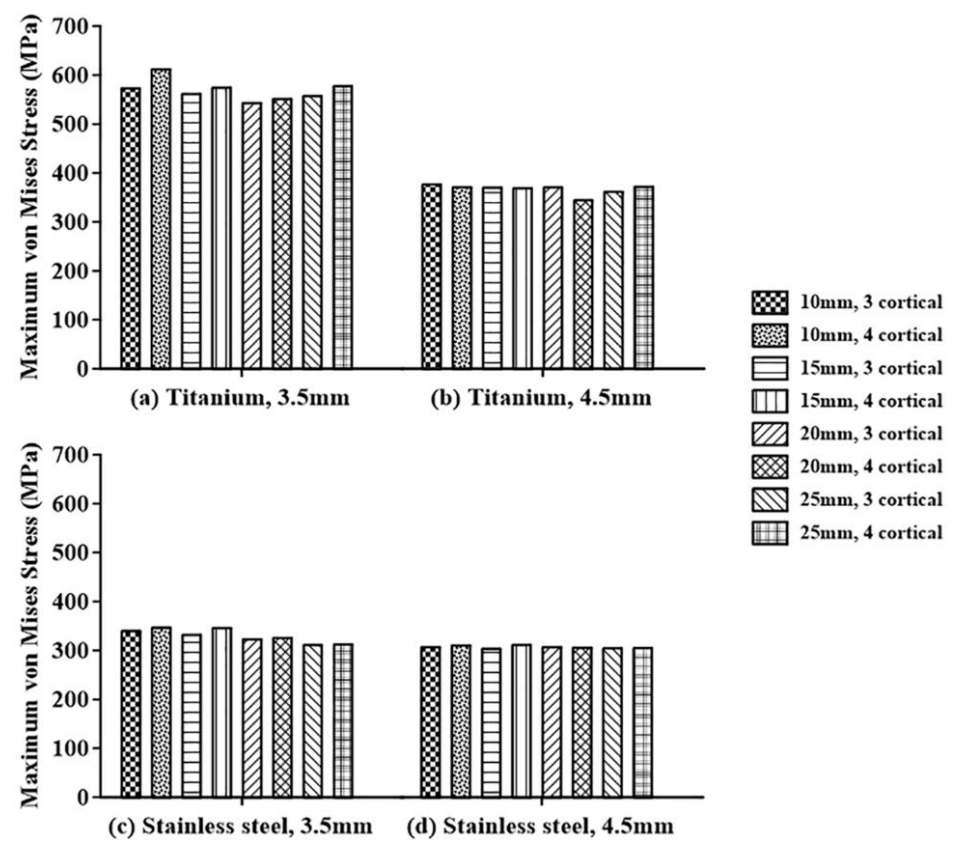

Figure 8. Analysis of the maximum von Mises stresses of the syndesmotic screw in terms of the number of penetrated cortical bones for: (a) titanium screw with a diameter of $3.5 \mathrm{~mm}$, (b) titanium screw with a diameter of $4.5 \mathrm{~mm}$, (c) stainless steel screw with a diameter of $3.5 \mathrm{~mm}$, and (d) stainless steel screw with a diameter of $4.5 \mathrm{~mm}$. 


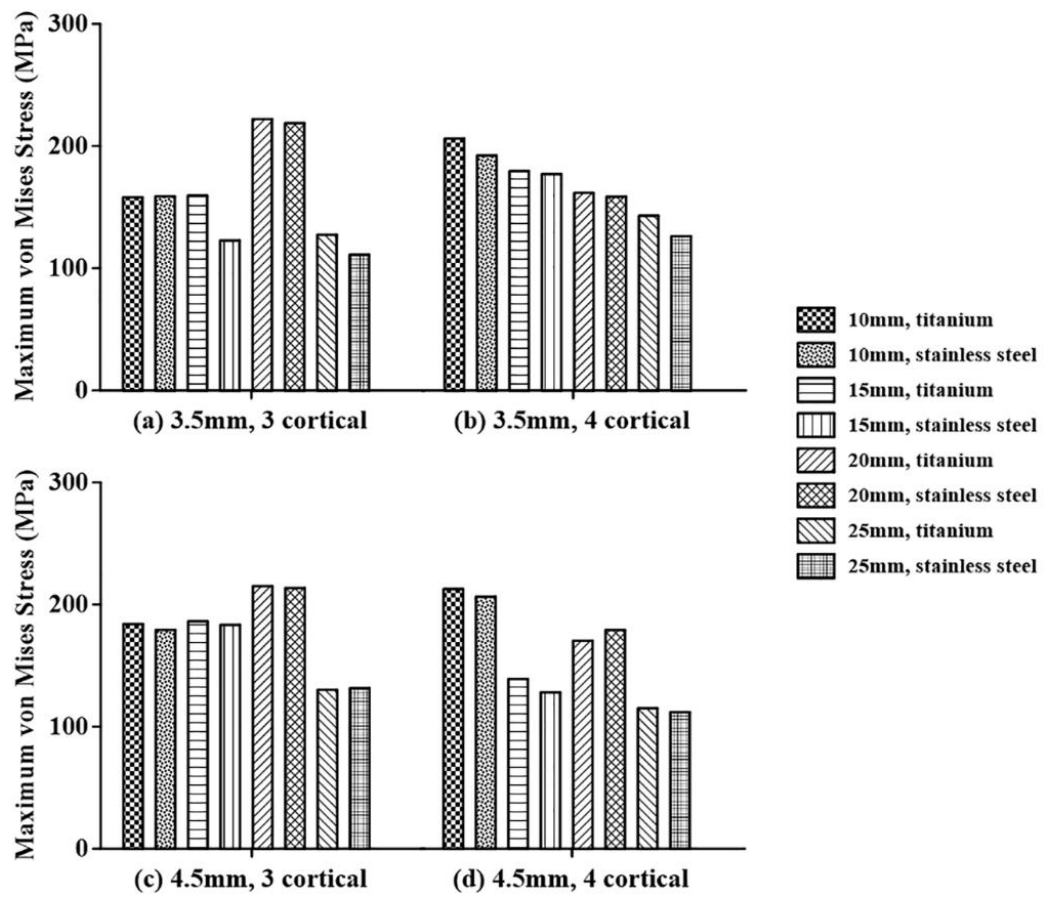

Figure 9. Analysis of the maximum von Mises stresses of the adjacent bone in terms of the screw material for screws with diameters of: (a) $3.5 \mathrm{~mm}$ penetrating three cortical bones, (b) $3.5 \mathrm{~mm}$ penetrating four cortical bones, (c) $4.5 \mathrm{~mm}$ penetrating three cortical bones, and (d) $4.5 \mathrm{~mm}$ penetrating four cortical bones.

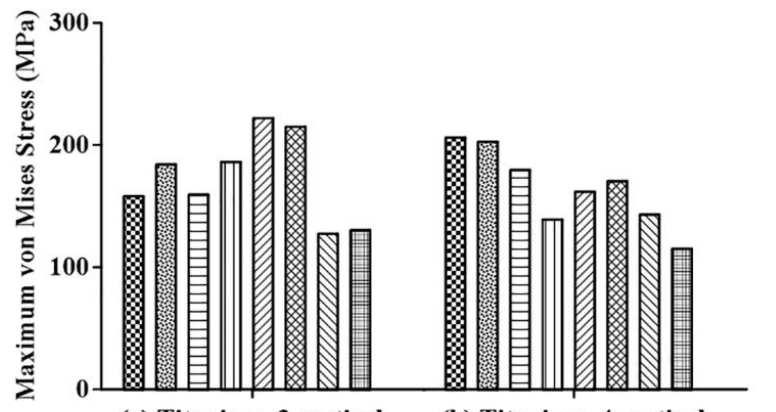

(a) Titanium, 3 cortical

(b) Titanium, 4 cortical

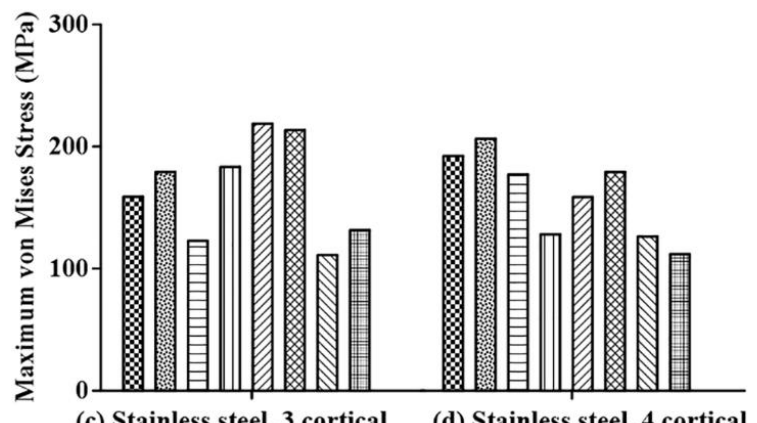

$\begin{array}{ll}\text { (c) Stainless steel, } 3 \text { cortical } & \text { (d) Stainless steel, } 4 \text { cortical }\end{array}$

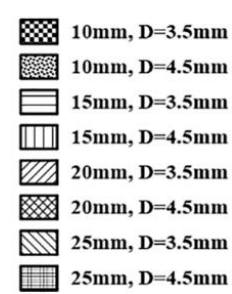

Figure 10. Analysis of the maximum von Mises stresses of the adjacent bone in terms of the diameter of the screw for: (a) titanium screw penetrating three cortical bones, (b) titanium screw penetrating four cortical bones, (c) stainless steel screw penetrating three cortical bones, and (d) stainless steel screw penetrating four cortical bones. 


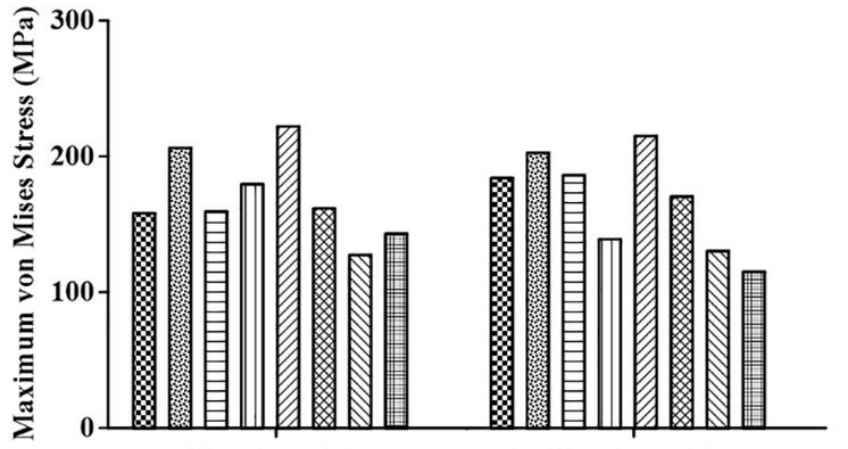

(a) Titanium, $3.5 \mathrm{~mm}$

(b) Titanium, $4.5 \mathrm{~mm}$

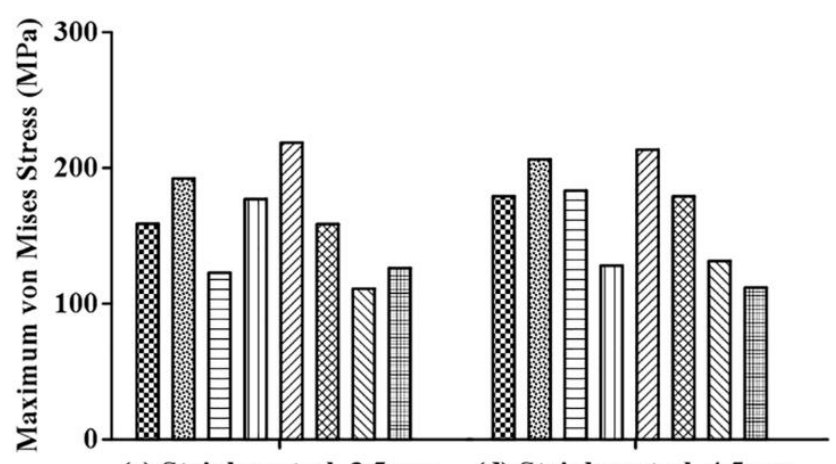

(c) Stainless steel, $3.5 \mathrm{~mm}$

(d) Stainless steel, $4.5 \mathrm{~mm}$

8. $10 \mathrm{~mm}, 3$ cortical

歷咚 $10 \mathrm{~mm}, 4$ cortical

E $15 \mathrm{~mm}, 3$ cortical

메 $15 \mathrm{~mm}, 4$ cortical

Q7 20mm, 3 cortical

$20 \mathrm{~mm}, 4$ cortical

MV $25 \mathrm{~mm}, 3$ cortical

$25 \mathrm{~mm}, 4$ cortical

Figure 11. Analysis of the maximum von Mises stresses of the adjacent bone in terms of the number of penetrated cortical bones for: (a) titanium screw with a diameter of $3.5 \mathrm{~mm}$, (b) titanium screw with a diameter of $4.5 \mathrm{~mm}$, (c) stainless steel screw with a diameter of $3.5 \mathrm{~mm}$, and (d) stainless steel screw with a diameter of $4.5 \mathrm{~mm}$.

Figures 9-11 are graphs for the maximum von Mises stresses of adjacent bone around the syndesmotic screw. In Figure 9, as the screw level increased, the stresses generally decreased with a few exceptions. On the other hand, there was no difference between the materials and diameter of the screw, and similar stresses were generated in Figures 9 and 10. The difference according to the number of penetrated cortical bones in Figure 11 shows that the stresses of the penetrating four cortical bone decrease as the level increases.

After measuring the displacements of the tibia and fibula, the difference between the two displacements was recorded as the widening value. Syndesmosis widening was determined to be at a distance of $15 \mathrm{~mm}$ from the tibia plafond in the $z$-axis direction. In Tables 5-8, the increase in the level is accompanied by the decrease in the syndesmosis widening value, regardless of the other parameters including the maximum von Mises stress. Figures 12-14 show the graphical representations of the results in terms of each parameter.

As shown in Figures 12-14, when the screw level is high, syndesmosis widening decreases. As shown in Figure 12, although the syndesmosis widening of a titanium screw at a screw level of $10 \mathrm{~mm}$ and diameter of $3.5 \mathrm{~mm}$ is longer than that of a stainless steel screw, syndesmosis widening is short in all other parts when using a titanium screw. As shown in Figure 13, syndesmosis widening for a diameter of $4.5 \mathrm{~mm}$ is shorter than that at a diameter of $3.5 \mathrm{~mm}$. There was inconsistency in syndesmosis widening according to the number of purchasing cortex. (Figure 14). 


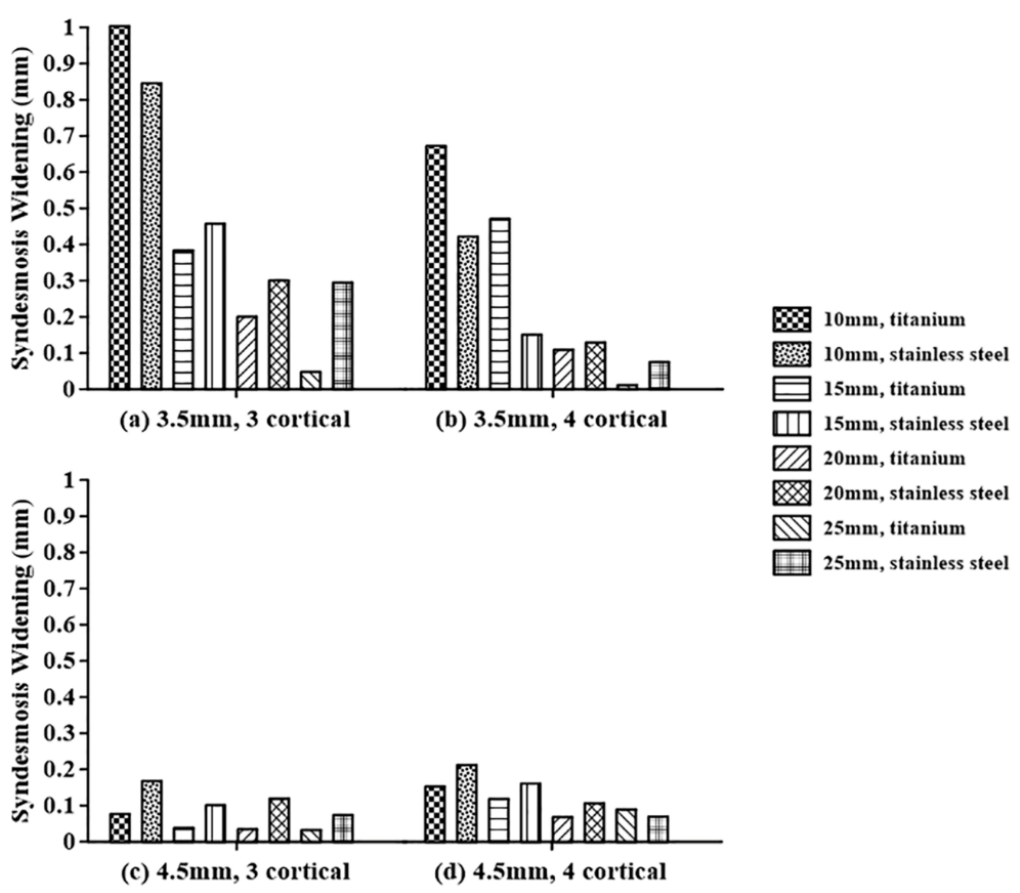

Figure 12. Analysis of the syndesmosis widening in terms of the screw material for screws with diameters of: (a) $3.5 \mathrm{~mm}$ penetrating into three cortical bones, (b) $3.5 \mathrm{~mm}$ penetrating into four cortical bones, (c) $4.5 \mathrm{~mm}$ penetrating into three cortical bones, and (d) $4.5 \mathrm{~mm}$ penetrating into four cortical bones.

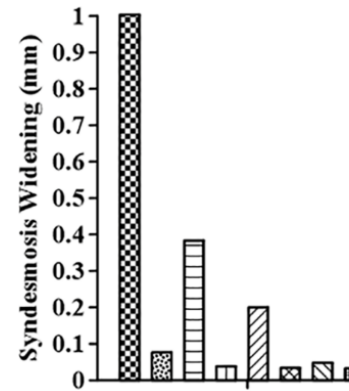

(a) Titanium, 3 cortical

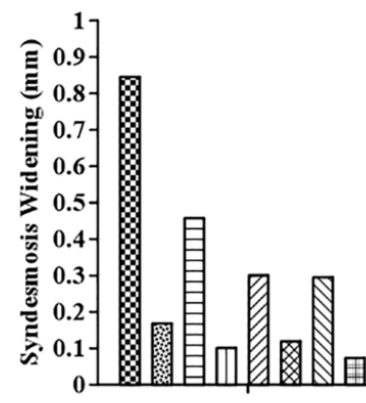

(c) Stainless steel, 3 cortical

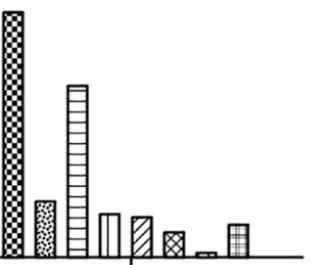

(b) Titanium, 4 cortical
Q $10 \mathrm{~mm}, \mathrm{D}=3.5 \mathrm{~mm}$

$10 \mathrm{~mm}, \mathrm{D}=4.5 \mathrm{~mm}$

$15 \mathrm{~mm}, \mathrm{D}=3.5 \mathrm{~mm}$

III $15 \mathrm{~mm}, \mathrm{D}=4.5 \mathrm{~mm}$

Z7 $20 \mathrm{~mm}, \mathrm{D}=3.5 \mathrm{~mm}$

$20 \mathrm{~mm}, \mathrm{D}=4.5 \mathrm{~mm}$

W $25 \mathrm{~mm}, \mathrm{D}=3.5 \mathrm{~mm}$

四 $25 \mathrm{~mm}, \mathrm{D}=4.5 \mathrm{~mm}$

Figure 13. Analysis of the syndesmosis widening in terms of the screw diameter for: (a) titanium screw penetrating into three cortical bones, (b) titanium screw penetrating into four cortical bones, (c) stainless steel screw penetrating into three cortical bones, and (d) stainless steel screw penetrating into four cortical bones. 


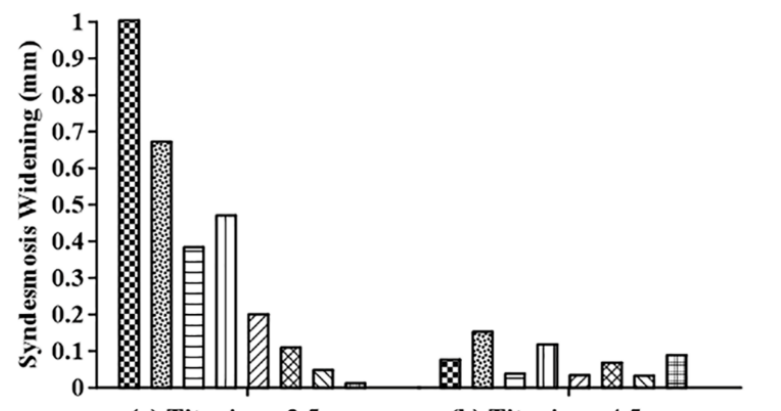

(a) Titanium, $3.5 \mathrm{~mm}$

(b) Titanium, $4.5 \mathrm{~mm}$

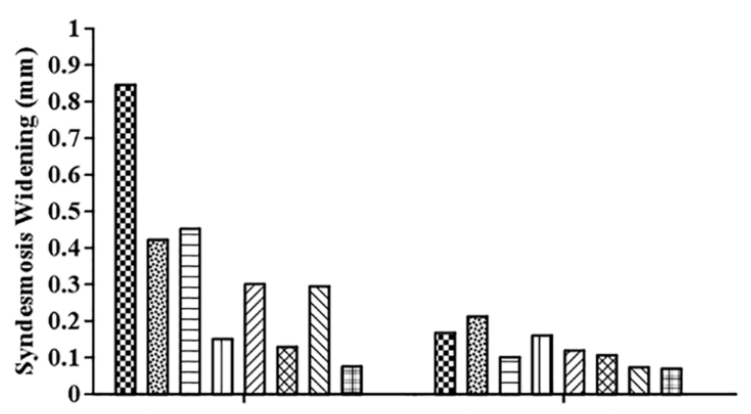

$\begin{array}{ll}\text { (c) Stainless steel, } 3.5 \mathrm{~mm} & \text { (d) Stainless steel, } 4.5 \mathrm{~mm}\end{array}$

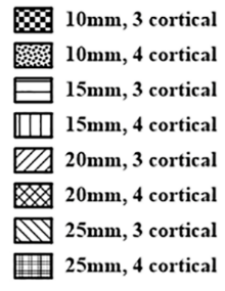

Figure 14. Analysis of the syndesmosis widening in terms of the number of penetrated cortical bones: (a) titanium screw with a diameter of $3.5 \mathrm{~mm}$, (b) titanium screw with a diameter of $4.5 \mathrm{~mm}$, (c) stainless steel screw with a diameter of $3.5 \mathrm{~mm}$, and (d) stainless steel screw with a diameter of $4.5 \mathrm{~mm}$.

\section{Discussion}

A syndesmosis injury leads to damage and loss of ligaments constituting the complex structure of the ankle joint because of the various external shocks and loads transferred to the tibia inside the body. Such a complex injury requires thorough research to cover various cases. Therefore, many studies have employed the FE analysis [25-28]. This study analyzed the effects of various parameters involved in screw fixation on the syndesmosis injury and determined an optimal location for screw fixation from a biomechanical perspective. To achieve these objectives, we set three parameters and derived the values of the maximum von Mises stresses and the syndesmosis widening.

In the first step of the analysis, the screw level was evaluated. The trend in the values was similar, regardless of the remaining parameters. In other words, with the increase in the screw level from 10 to $25 \mathrm{~mm}$, the stress and the syndesmosis widening were decreased, irrespective of the diameter and material of the screw and the number of penetrated cortical bones. The decrease in the stress indicates that, as the screw level increases, the stress acting on the screw is greater than that on the bone. In addition, even after checking the stress on the adjacent bone of the screw, the stress decreased as the level increased. The decrease in the syndesmosis widening indicates that the binding force between the bone and the screw is strong. Accordingly, if the screw is positioned at a level in the range of $20-25 \mathrm{~mm}$, the stability of the syndesmosis increases. This result is supported by many other cadaveric biomechanical studies wherein similar values have been reported [6,29].

The analysis in the second step was conducted in terms of the material of the syndesmotic screw, such as titanium and stainless steel. The stress acting on the stainless steel screws is lower than that acting on the titanium ones. However, when the elasto-plastic properties of the two materials were compared, the maximum stress of titanium did not exceed the yield stress, whereas that of stainless steel exceeded the yield stress $[16,20,21,30]$. In addition, with respect to syndesmosis widening, the results of the widening show a firm basis for selecting a more appropriate material. Although the difference between the two materials did not occur in the stresses on the adjacent bone of the screw, the other results concluded that titanium is more stable than stainless steel. Beumer et al. conducted a cadaveric 
study and presented experimental results obtained by applying a force of $800 \mathrm{~N}$ to sixteen fresh frozen legs inserted with syndesmotic screws, which were fabricated from either stainless steel or titanium and had three or four cortical rolls. The results were found to be similar on the basis of the two parameters used, and it was specified that under no condition should a weight bearing load be applied [8]. However, unlike previous cadaveric studies, this study shows the relative advantages of the two materials. The internal stresses of the bones and screw were analyzed using an FE analysis. The results show that titanium exhibits a higher level of stability.

In the third step of the analysis, we compared the von Mises stresses in terms of two different screw diameters: 3.5 and $4.5 \mathrm{~mm}$. For most cases, the stress on the screw with a diameter of $4.5 \mathrm{~mm}$ is lower than that on the screw with a diameter of $3.5 \mathrm{~mm}$. In addition, with regard to the syndesmosis widening, the preferable screw has a diameter of $4.5 \mathrm{~mm}$. However, there was no difference between the two diameters in the stresses of the adjacent bone of the screw. Consequently, we may conclude that a screw with a diameter of $4.5 \mathrm{~mm}$ is more advantageous than that with a diameter of $3.5 \mathrm{~mm}$. Thompson and Gesink evaluated the stability of twelve cadaveric leg specimens inserted with stainless steel syndesmotic screws with diameters of 3.5 and $4.5 \mathrm{~mm}$. The sub-maximal axial ramp (0 to $1200 \mathrm{~N})$ test and the axial fatigue test $(0$ to $900 \mathrm{~N})$ were conducted on the specimens. They concluded that the screws with diameters of 3.5 and $4.5 \mathrm{~mm}$ did not exhibit any biomechanical difference in syndesmotic fixation [31]. In contrast, the simulation results of this study show that a screw with a diameter of $4.5 \mathrm{~mm}$ is more advantageous. Accordingly, this study supplements the cadaveric studies. However, in another cadaveric study, Hansen et al. applied four cortical techniques to eighteen specimens for inserting screws with diameters of 3.5 and $4.5 \mathrm{~mm}$ and measured the shear stresses. Because the yield and peak loads of the screw with the diameter of $4.5 \mathrm{~mm}$ were higher than those of the screws with the diameter of $3.5 \mathrm{~mm}$, they concluded that the larger the screw diameter, the greater is the resistance of the screw to shear stresses [32]. Hence, we believe the screw diameter should be selected on the basis of a comprehensive examination including the FE analysis of the shear stress.

In the fourth step of the analysis, we examined the biomechanical effect of the number of penetrated cortical bones on syndesmosis fixation. With regard to the two cases wherein three and four cortical bones were penetrated, the stress was no different in all cases. With respect to the values of syndesmosis widening, these were lower in the case wherein four cortical bones were penetrated compared with those in the case wherein three cortical bones were penetrated for a diameter of $3.5 \mathrm{~mm}$. However, there was no difference for a diameter of $4.5 \mathrm{~mm}$. The widening in the case wherein four cortical bones were penetrated was lower, but as the diameter increased, its influence decreased. On the other hand, the stresses at the adjacent bone of the penetrating four cortical bones decrease as the level increases. In another cadaveric study, Beumer et al. concluded that the number of penetrated cortical bones made no biomechanical difference. Moore et al. checked the conditions of patients for 150 days after syndesmotic fixation. The screw failure was $8 \%$ among patients who secured stability through three cortical fixations, whereas the screw failure in patients treated with four cortical fixations was $7 \%$. Based on this data, it was speculated that both three and four cortical fixation techniques were useful for ensuring stability of the syndesmosis. Moreover, they showed that the stability in the case of three cortical fixations tended to decrease when no weight restriction was imposed [33]. This can be verified using the FE analysis results of this study, wherein it is demonstrated that the stability in the case of three and four cortical fixations are high.

Many parameters can be employed in a cadaveric or FE analysis to identify the biomechanical characteristics of the syndesmotic screw fixation. In addition to the parameters employed in this study, such as the level, material, and diameter of the screw and the number of cortical bone penetrations, many other parameters exist including the density of cancellous bone according to age and sex of patients, the number of fixed screws, load conditions (compressive and rotation forces), phases of human walking, and surgical conditions. In particular, the external rotational motion of the ankle joint is a major factor in ligament injury. Accordingly, it will be the subject of future study. 
The finite element analysis was carried out by substituting the change according to the number of screws in this study among these limit conditions. Another screw was added based on the parameters at the $4.5 \mathrm{~mm}$ diameter and $25 \mathrm{~mm}$ level of the titanium screw with four cortical bones, from the results of this study. This involves inserting two screws by adding one screw of another level to a $25 \mathrm{~mm}$ level screw. Analysis was performed by inserting screws at levels of 10 and $15 \mathrm{~mm}$ respectively, as shown in Figure 15.

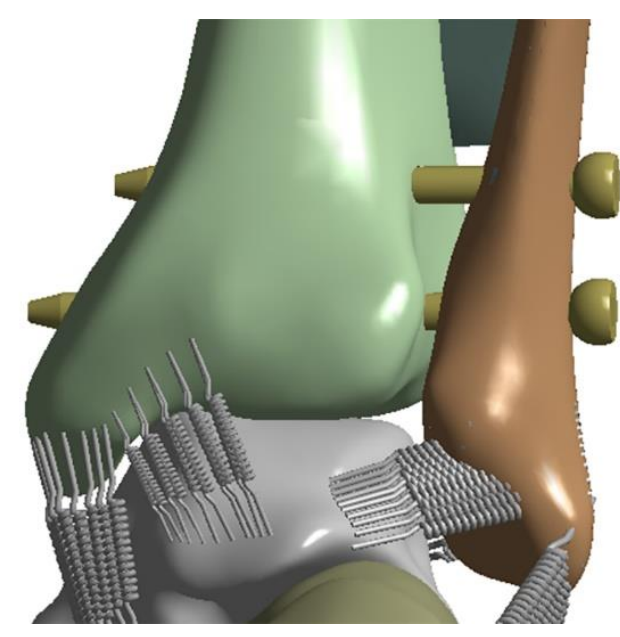

(a)

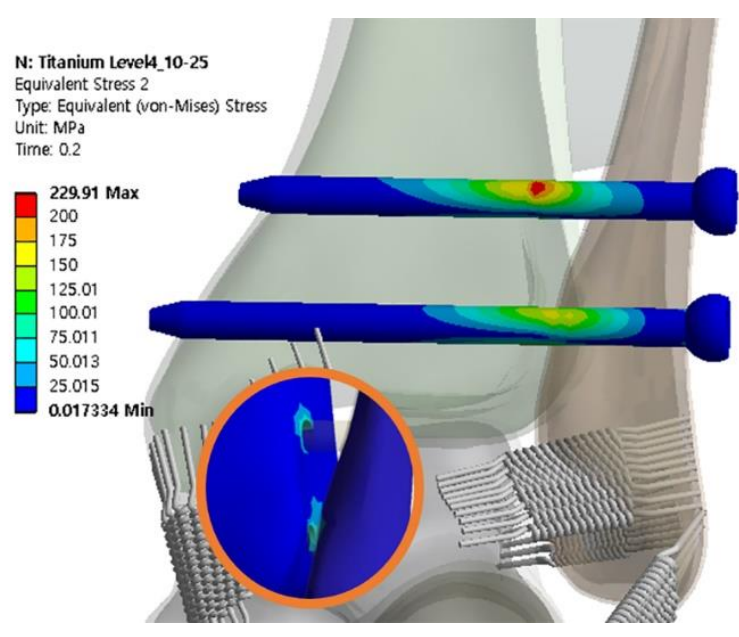

(b)

Figure 15. Finite element model and distribution of maximum equivalent stress with screws inserted at levels of 10 and $25 \mathrm{~mm}$ : (a) finite element model of syndesmotic fixation with double screws, and (b) maximum equivalent stresses of the screws and adjacent bone.

According to Table 9, the maximum equivalent stress and syndesmosis widening were lowered by adding screws. It can also be seen that the higher the relative level of the two screws, the lower the stress and widening. The clinical opinion on the addition of a screw was found to be also advantageous mechanically through finite element analysis. However, since such a fragmentary analysis cannot be confirmed, a more detailed interpretation will be carried out through future study.

Table 9. Maximum von Mises stresses and syndesmosis widening: double titanium screw of 4.5 diameter with four cortical bones.

\begin{tabular}{cccc}
\hline \multirow{2}{*}{ Level (mm) } & \multicolumn{2}{c}{ Maximum von Mises Stress (MPa) } & \multirow{2}{*}{ Syndesmosis Widening (mm) } \\
\cline { 2 - 3 } & Screw & Adjacent Bone & \\
\hline 25 & 372.05 & 115.01 & 0.0891 \\
15 and 25 & 261.96 & 103.66 & 0.1008 \\
10 and 25 & 229.91 & 98.30 & 0.0786 \\
\hline
\end{tabular}

\section{Conclusions}

The following are the conclusions of this study: The level of the syndesmotic screw is the most influential factor with regard to stabilizing the syndesmosis. With the increase in the level, the stability increases. We recommend fixing a titanium screw with a diameter of $4.5 \mathrm{~mm}$ by penetrating three or four cortical bones at a level of $20-25 \mathrm{~mm}$ above the ankle joint. However, analysis did not include various clinical conditions such as the rotation force and fracture pattern, so it is considered that further study is necessary.

Author Contributions: Conceptualization, T.S.G. and C.-S.L.; data curation, T.S.G., B.-Y.L., J.S.L. and C.-S.L.; formal analysis, B.-Y.L. and C.-S.L.; funding acquisition, T.S.G., J.S.L. and C.-S.L.; investigation, T.S.G., B.-Y.L. and 
C.-S.L.; methodology, T.S.G., B.-Y.L. and C.-S.L.; project administration, T.S.G., J.S.L. and C.-S.L.; resources, T.S.G. and J.S.L.; software, B.-Y.L.; supervision, J.S.L. and C.-S.L.; validation, T.S.G., B.-Y.L. and C.-S.L.; visualization, B.-Y.L.; writing—original draft, T.S.G. and B.-Y.L.; writing—review and editing, T.S.G., B.-Y.L., J.S.L. and C.-S.L. All authors have read and agreed to the published version of the manuscript.

Funding: This research was supported by the Basic Science Research Program through the National Research Foundation of Korea (NRF), funded by the Ministry of Education. (No. NRF-2018R1D1A1B07047666, TSG). It was also supported by the National Research Foundation of Korea (NRF) grant funded by the Korea government (MSIT). (No. NRF-2018R1A2B6007351, JSL; No. NRF-2019R1F1A1062037, CSL).

Conflicts of Interest: The authors declare no conflict of interest. The funders had no role in the study design, data collection and analyses, writing of the manuscript, or in the decision to publish the results.

\section{References}

1. Schepers, T.; Van Lieshout, E.M.; de Vries, M.R.; Van der Elst, M. Complications of syndesmotic screw removal. Foot Ankle Int. 2011, 32, 1040-1044. [CrossRef]

2. Lauge-Hansen, N. Fractures of the ankle: II. Combined experimental-surgical and experimentalroentgenologic investigations. Arch. Surg. 1950, 60, 957-985. [CrossRef] [PubMed]

3. Wuest, T.K. Injuries to the distal lower extremity syndesmosis. J. Am. Acad. Orthop. Surg. 1997, 5, $172-181$. [CrossRef] [PubMed]

4. Peek, A.; Fitzgerald, C.; Charalambides, C. Syndesmosis screws: How many, what diameter, where and should they be removed? A literature review. Injury 2014, 45, 1262-1267. [CrossRef] [PubMed]

5. Hamid, N.; Loeffler, B.; Braddy, W.; Kellam, J.; Cohen, B.; Bosse, M. Outcome after fixation of ankle fractures with an injury to the syndesmosis. Bone Jt. J. 2009, 91, 1069-1073. [CrossRef] [PubMed]

6. McBryde, A.; Chiasson, B.; Wilhelm, A.; Donovan, F.; Ray, T.; Bacilla, P. Syndesmotic screw placement: A biomechanical analysis. Foot Ankle Int. 1997, 18, 262-266. [CrossRef]

7. van den Bekerom, M.P.; Hogervorst, M.; Bolhuis, H.W.; van Dijk, C.N. Operative aspects of the syndesmotic screw: Review of current concepts. Injury 2008, 39, 491-498. [CrossRef]

8. Beumer, A.; Campo, M.M.; Niesing, R.; Day, J.; Kleinrensink, G.-J.; Swierstra, B.A. Screw fixation of the syndesmosis: A cadaver model comparing stainless steel and titanium screws and three and four cortical fixation. Injury 2005, 36, 60-64. [CrossRef]

9. Er, M.S.; Verim, O.; Altinel, L.; Tasgetiren, S. Three-dimensional finite element analysis used to compare six different methods of syndesmosis fixation with 3.5- or 4.5-mm titanium screws: A biomechanical study. J. Am. Podiatr. Med. Assoc. 2013, 103, 174-180. [CrossRef]

10. Liu, Q.; Zhang, K.; Zhuang, Y.; Li, Z.; Yu, B.; Pei, G. Analysis of the stress and displacement distribution of inferior tibiofibular syndesmosis injuries repaired with screw fixation: A finite element study. PLoS ONE 2013, 8, e80236. [CrossRef]

11. Verim, O.; Serhan Er, M.; Altinel, L.; Tasgetiren, S. Biomechanical Evaluation of Syndesmotic Screw Position: A Finite-Element Analysis. J. Orthop. Trauma 2014, 28, 210-215. [CrossRef] [PubMed]

12. Liu, Q.; Zhao, G.; Yu, B.; Ma, J.; Li, Z.; Zhang, K. Effects of inferior tibiofibular syndesmosis injury and screw stabilization on motion of the ankle: A finite element study. Knee Surg. Sports Traumatol. Arthrosc. 2016, 24, 1228-1235. [CrossRef] [PubMed]

13. Attarian, D.E.; McCrackin, H.J.; DeVito, D.P.; McElhaney, J.H.; Garrett, W.E., Jr. Biomechanical characteristics of human ankle ligaments. Foot Ankle 1985, 6, 54-58. [CrossRef] [PubMed]

14. Pfaeffle, H.J.; Tomaino, M.M.; Grewal, R.; Xu, J.; Boardman, N.D.; Woo, S.L.Y.; Herndon, J.H. Tensile properties of the interosseous membrane of the human forearm. J. Orthop. Res. 1996, 14, 842-845. [CrossRef]

15. Taylor, M.; Tanner, K.; Freeman, M. Finite element analysis of the implanted proximal tibia: A relationship between the initial cancellous bone stresses and implant migration. J. Biomech. 1998, 31, 303-310. [CrossRef]

16. Rasmussen, K.J. Full-range stress-strain curves for stainless steel alloys. J. Constr. Steel Res. 2003, 59, 47-61. [CrossRef]

17. Kemper, A.; McNally, C.; Kennedy, E.; Manoogian, S.; Duma, S. The material properties of human tibia cortical bone in tension and compression: Implications for the tibia index. In Proceedings of the 20th Enhanced Safety of Vehicles Conference, Lyon, France, 18-21 June 2007.

18. Walke, W.; Paszenda, Z.; Kaczmarek, M. Biomechanical analysis of tibia-double threaded screw fixation. Arch. Mater. Sci. Eng. 2008, 30, 41-44. 
19. Chen, C.; Cheng, Y.; Cheng, H.; Wen, J.; Zhao, J.; Hou, W.; Zhu, J.; Qiu, P. Finite element analysis of the stress concentration in pronation-abduction ankle joint injuries. Int. J. Clin. Exp. Med. 2017, 10, $276-284$.

20. Conway, J.B.; Stentz, R.; Berling, J. Fatigue, Tensile, and Relaxation Behavior of Stainless Steels; Mar-Test, Inc.: Cincinnati, OH, USA, 1975.

21. Oliveira, D.; Prokofiev, E.; Sanches, L.; Polyakova, V.; Valiev, R.; Botta, W.; Junior, A.; Bolfarini, C. Surface chemical treatment of ultrafine-grained $\mathrm{Ti}-6 \mathrm{Al}-7 \mathrm{Nb}$ alloy processed by severe plastic deformation. J. Alloy. Compd. 2015, 643, S241-S245. [CrossRef]

22. Koistinen, A. Improvement of The Orthopaedic Bone Screws by DLC Coatings; Academic Dissertation, University of Eastern Finland: Kuopio, Finland, 30 November 2012.

23. Piper, A.T. Modelling Cancellous Bone Screw Performance Using Finite Element Models. Ph.D. Thesis, Brunel University, London, UK, 2016.

24. Haraguchi, N.; Armiger, R.S.; Myerson, M.S.; Campbell, J.T.; Chao, E.Y. Prediction of three-dimensional contact stress and ligament tension in the ankle during stance determined from computational modeling. Foot Ankle Int. 2009, 30, 177-185. [CrossRef]

25. Chen, W.-P.; Tang, F.-T.; Ju, C.-W. Stress distribution of the foot during mid-stance to push-off in barefoot gait: A 3-D finite element analysis. Clin. Biomech. 2001, 16, 614-620. [CrossRef]

26. Reggiani, B.; Leardini, A.; Corazza, F.; Taylor, M. Finite element analysis of a total ankle replacement during the stance phase of gait. J. Biomech. 2006, 39, 1435-1443. [CrossRef] [PubMed]

27. Zhang, M.-Y.; Xu, C.; Li, K.-H. Finite element analysis of nonanatomic tenodesis reconstruction methods of combined anterior talofibular ligament and calcaneofibular ligament deficiency. Foot Ankle Int. 2011, 32, 1000-1008. [CrossRef] [PubMed]

28. Xu, C.; Zhang, M.-Y.; Lei, G.-H.; Zhang, C.; Gao, S.-G.; Ting, W.; Li, K.-H. Biomechanical evaluation of tenodesis reconstruction in ankle with deltoid ligament deficiency: A finite element analysis. Knee Surg. Sports Traumatol. Arthrosc. 2012, 20, 1854-1862. [CrossRef] [PubMed]

29. Miller, R.; Weinhold, P.; Dahners, L. Comparison of tricortical screw fixation versus a modified suture construct for fixation of ankle syndesmosis injury: A biomechanical study. J. Orthop. Trauma 1999, 13, $39-42$. [CrossRef] [PubMed]

30. Ziaja, W. Finite element modelling of the fracture behaviour of surface treated Ti-6Al-4V alloy. System 2009, $16,17$.

31. Thompson, M.C.; Gesink, D.S. Biomechanical comparison of syndesmosis fixation with 3.5- and 4.5-millimeter stainless steel screws. Foot Ankle Int. 2000, 21, 736-741. [CrossRef]

32. Hansen, M.; Le, L.; Wertheimer, S.; Meyer, E.; Haut, R. Syndesmosis fixation: Analysis of shear stress via axial load on 3.5-mm and 4.5-mm quadricortical syndesmotic screws. J. Foot Ankle Surg. 2006, 45, 65-69. [CrossRef]

33. Moore, J.A., Jr.; Shank, J.R.; Morgan, S.J.; Smith, W.R. Syndesmosis fixation: A comparison of three and four cortices of screw fixation without hardware removal. Foot Ankle Int. 2006, 27, 567-572. [CrossRef]

(C) 2020 by the authors. Licensee MDPI, Basel, Switzerland. This article is an open access article distributed under the terms and conditions of the Creative Commons Attribution (CC BY) license (http://creativecommons.org/licenses/by/4.0/). 